\title{
Hospitalization due to stroke and myocardial infarction in self-employed individuals and small business owners compared with paid employees in Sweden-a 5-year study
}

\author{
Susanna Toivanen • Rosane Härter Griep • \\ Christin Mellner • Mikael Nordenmark • \\ Stig Vinberg • Sandra Eloranta
}

Accepted: 26 February 2018/Published online: 16 April 2018

(C) The Author(s) 2018

\begin{abstract}
Analysing Swedish population register data, the aim of the present study is to investigate differences in acute cardiovascular disease (CVD) in terms of stroke and myocardial infarction incidence between selfemployed individuals and paid employees and to study whether the associations vary by gender or across industrial sectors. A cohort of nearly 4.8 million employed individuals (6.7\% self-employed in 2003) is followed-up
\end{abstract}

Electronic supplementary material The online version of this article (https://doi.org/10.1007/s11187-018-0051-3) contains supplementary material, which is available to authorized users.

\section{S. Toivanen $(\bowtie) \cdot$ R. Härter Griep}

Department of Public Health Sciences, Stockholm University, SE-106 91 Stockholm, Sweden

e-mail: susanna.toivanen@su.se

S. Toivanen

School of Health, Care and Social Welfare, Mälardalen University, Västerås, Sweden

R. Härter Griep

Laboratory of Health and Environment Education, Oswaldo Cruz Institute, Oswaldo Cruz Foundation (Fiocruz), Rio de Janeiro, Brazil

\section{Mellner}

Department of Psychology, Stockholm University, Stockholm, Sweden

\section{Nordenmark $\cdot$ S. Vinberg}

Department of Health Sciences, Mid Sweden University,

Sundsvall, Sweden

\section{S. Eloranta}

Scandinavian Development Services, Stockholm, Sweden for hospitalization due to stroke and myocardial infarction (2004-2008). Self-employed individuals are defined as sole proprietors and limited liability company owners according to legal type of their enterprise. Negative binomial regression models are applied to compare hospitalization rates between the self-employed and paid employees, adjusted for socioeconomic and demographic confounders. Two- and three-way interaction are tested between occupational group, industrial sector, and gender. Limited liability company owners have significantly lower hospitalization for myocardial infarction than paid employees. Regarding two-way interaction, sole proprietors have higher myocardial infarction hospitalization in trade, transport and communication, and lower in agriculture, forestry, and fishing than paid employees. Limited liability company owners have lower hospitalization rate for myocardial infarction than employees in several industries. The results highlight the importance of enterprise legal type and industrial sector for CVD among self-employed individuals.

Keywords Self-employment - Cardiovascular disease . Hospitalization · Sweden

JEL classification I14 $\cdot$ I1 $\cdot$ J2 $1 \cdot J 81 \cdot$ L22 $\cdot$ L26

\section{Introduction}

Labour markets are changing due to digitalization and economic globalization, giving rise to new forms of employment (Grosheide and Barenberg 2015). As a 
consequence, self-employment is increasingly common in many countries, and the proportion varies between 7 and $30 \%$ of the working populations in European countries (Hatfield 2015). Despite their large proportion of the working populations, the self-employed are still a neglected group in international occupational safety and health $(\mathrm{OSH})$ research (Pedersini and Coletto 2010). For instance, at the 7th International Conference on Work Environment and Cardiovascular Diseases organized by ICOH (International Commission on Occupational Health 2017), only one presentation focused specifically on self-employed workers and one focused on farmers. Research reviews on working conditions and health among the self-employed are scarce (Stephan 2018). A general finding from previous studies comparing the self-employed and paid employees is that the selfemployed tend to have more job control, work longer hours, have shorter vacations, and are not able to take sick leave to the same extent as employees (Andersson 2007). Thus, they are more likely to have higher sickness presence than employees meaning that they go to work even though their health status imply they would need to take sick leave (Aronsson and Gustafsson 2005; Knani et al. 2015). Yet, research into health differences between self-employed individuals and paid employees is somewhat inconclusive due to variation of study design and methodology. Most studies have focused on general and mental health outcomes (e.g. Jamal 1997; Vinberg et al. 2013). Generally, previous research suggests that the self-employed have better health than paid employees (Stephan and Roesler 2010; Andersson 2008; Yoon and Bernell 2013) although contradicting results exist (Rietveld et al. 2015; Gunnarsson et al. 2007; Dolinsky and Caputo 2003), as well as differences between women and men (Nordenmark et al. 2012), and between immigrant and natives (Sevä et al. 2016).

For CVD, there are few studies on the self-employed. In a cross-sectional study based on a national representative sample, Stephan and Roesler (2010) report lower blood pressure, lower prevalence rates of hypertension, as well as higher well-being and more favorable behavioral health indicators among entrepreneurs than employees. Studies into mortality among the selfemployed report $23 \%$ higher mortality from CVD among individuals in trade, transport, and communication compared with those in agriculture, forestry, and fishing (Toivanen et al. 2015). In general, mortality is reported to be higher in self-employed that operate as sole proprietors compared with those that run a limited liability company (Toivanen et al. 2015). One study reports lower mortality from CVD among limited liability company (LLC) owners than among paid employees (Toivanen et al. 2016).

CVD is the leading global cause of death (WHO 2017), accounting for 17.5 million deaths per year, a number that is expected to grow to more than 23.6 million by 2030 (Mckay et al. 2005; WHO 2016b). Among CVD, the main killers are stroke and ischaemic heart disease including myocardial infarction (MI). In addition to biological and lifestyle-related risk factors, several social- and work-related factors confer an increased risk of CVD, e.g. low socio-economic position defined as low educational level, low occupational class, or low income (Hobbs et al. 2016). This may be explained by dominance hierarchies suggesting that dominant members of a group have better cardiovascular health compared to subordinate group members (Sapolsky 2005). The stepwise social gradient of cardiovascular disease with higher risk among those with lower socio-economic position compared to those with higher position is explained partly by social gradients in health behaviors (Brunner 2017). Yet, three decades of research provide evidence for a psychosocial pathway in terms of job stress leading to cardiovascular morbidity and mortality (Brunner 2017.) Chronic stress at work in terms of long working hours, extensive overtime work, high psychological demands, low job control, job strain, and unfairness are associated with increased risk for CVD (Hobbs et al. 2016)How chronic stress effects cardiovascular health depends on other simultaneous factors. For instance, the literature on social modulation of stress response suggests that social support and affiliation provide a buffering effect that reduces the adverse impact of stress on health (DeVries et al. 2003). A recent study shows that the self-employed suffer from less work-related stress than paid employees, and that the negative relationship between selfemployment and work-related stress was fully mediated by job control (Hessels et al. 2017). However, previous studies of social and work related factors and risk of CVD mainly focus on paid employees (Kivimäki and Kawachi 2015). Thus, our present knowledge about CVD in general, and stroke and myocardial infarction in particular, 
among the self-employed in relation to paid employees is limited.

Even if the self-employed are more likely to have higher sickness presence than paid employees, yet with regard to acute severe CVD such as stroke or myocardial infarction, which require immediate hospital care, there might not be differences between the occupational groups. To our knowledge, the question has not been thoroughly investigated. Hospitalization and mortality data are particularly useful when comparing health status between different occupational groups. Differences in hospitalization cannot be explained by differential reporting, which is an inherent issue in studies based on self-reported data. Therefore, based on analyses of Swedish administrative register data, the main aim of the present explorative study is to estimate the risk of hospitalization due to stroke or myocardial infarction by occupational group considering repeat hospital episodes. Because the Swedish labour market is segregated by gender and because mortality risk varies by industry, we also investigate how risk of hospitalization depend on gender and industrial sector.

\section{Data and methods}

\subsection{Data}

Data were obtained from the Swedish Work and Mortality Database maintained at the Centre for Health Equity Studies, Stockholm University/ Karolinska Institutet. Ethical permission (no. 02481) was provided by the Regional Ethics Committee in Stockholm. The database comprises several administrative registers provided by Statistics Sweden and the National Board of Health and Welfare, of which the Total Population Register, Longitudinal Database on Education, Income and Employment (LOUISE), the Hospital Discharge Register and the Cause of Death Register were used in the present analyses. Record linkages were possible using an encrypted version of 10-digit personal identity number provided by authorities to ensure anonymity.

\subsection{Study population and follow-up}

The population included all self-employed persons and paid employees as recorded in the Swedish registry
2003. After excluding persons with missing values on central variables, the final cohort consisted of 211,464 self-employed persons registered as sole proprietors (31\% women), 109,809 self-employed persons registered as limited liability company owners (27\% women), and 4,454,845 employees (50\% women). Age ranged between 18 and 100 years and the proportion of individuals $<65$ years of age was $89.5 \%$ among sole proprietors, $94.8 \%$ among LLC owners, and $96.6 \%$ among paid employees. Thus, $10.5 \%$ of the selfemployed are older than 65 years, which is the reason for keeping the present age-range.

The cohort was followed for recurrent hospitalizations for stroke and myocardial infarction, respectively, by record linkage to the Hospital Discharge Register 2004-2008. Each participant was considered at risk for hospitalization from the date of inclusion to the study (1 January 2004) until the date of death, emigration, or end of the study (31 December 2008), whichever came first.

2.3 Assessment of exposures, covariates, and outcomes

\subsubsection{Occupational group}

In Swedish labour statistics, a business owner is defined as a physical person engaged in active business (selfemployed) or a limited liability company owner having his or her principal employment within the company (Statistics Sweden 2007). In the data, a person's occupational group is stated as (1) employee, (2) selfemployed as sole proprietor, or (3) limited liability company owner (LLC). In this study, all occupational groups were selected. Employees were used as the reference category. Sociodemographic and health-related differences between sole proprietors and LLC owners in relation to employees have been reported elsewhere (Toivanen et al. 2016; Toivanen et al. 2015) and are included in Appendices 1 through 3 which are available online. Briefly, sole proprietors and LLC company owners are older, a smaller proportion of them have tertiary education and their health is slightly poorer compared with employees (Toivanen et al. 2016). While the largest proportion of employees operate in welfare sectors including services mainly provided by the welfare state such as education and health care, a substantial share of the self-employed work in trade, transport, and communication. 


\subsubsection{Industrial sector}

The Swedish Standard Industrial Classification (SNI 2002) that corresponds to NACE Rev. 1.1 (EU level) and ISIC Rev. 3 (world level) was used to classify industrial sectors (European Commission and Eurostat 2013; Statistics Sweden 2004). The highest aggregate level identified by an alphabetical code was used to collapse industries into eight categories: agriculture, forestry, and fishing (AFF); manufacturing and mining (MM); construction (C); trade, transport, and communication (TTC); financial intermediation, business activities (FB); personal and cultural services, including hotels and restaurants (PCS); sector not specified (NS); and welfare (W). W includes services mainly provided by the welfare state such as education, research, health and social care, and electricity, gas, and water supply. AFF was used as the reference category. Previous research shows that AFF has lower mortality risk compared to other industries as regards to all-cause mortality, and mortality from CVD and neoplasms, but higher mortality from suicide than other industries (Toivanen et al. 2015).

\subsubsection{Assessment of covariates}

Age at entry to the study was included as a continuous and squared variable, respectively. Sole proprietors and LLC owners are slightly older than paid employees, and the risk of CVD increases with age (Toivanen et al. 2015). Gender was included as women and men work largely in different industrial sectors. Also, the incidence of stroke and myocardial infarction, respectively, has previously been shown to depend of gender (Toivanen 2008). The primary regression analysis was performed adjusting for gender as a main effect. However, effect modification by gender was formally tested in a secondary analysis to assess the need for a gender-stratified analysis. Country of origin was classified as Sweden or elsewhere. Previous research shows that selfemployment is more common in immigrant groups than natives in Sweden (Joona and Wadensjö 2008). Education was categorized into four groups: primary, secondary, tertiary, and unknown education. Most health outcomes including CVD have a social gradient indicating poorer health in lower socioeconomic positions than in higher positions and a gradient for the intermediate positions (Kuper et al.
2007). Family structure was categorized into five groups: living alone, lone parent, cohabiting (married or cohabiting), cohabiting parent, unknown. Previous results show that cohabiting is more frequent among self-employed individuals than employees (Toivanen et al. 2016). Cohabiting may influence getting medical help quicker. Number of children was grouped into small children (ages 0-6) and older children (ages 7-17) and included as a continuous variable. Location was categorized as urban or rural based on place of residence as distance to hospital may influence individuals' access to specialized care. Also, most self-employed operate in urban areas. Health status before baseline may influence the risk of hospitalization during followup and was adjusted for in terms of the Charlson Comorbidity Index (Charlson 1987). Conditions included in the index cover a large variety of somatic diseases, and the index was calculated from ICD-10 codes available in the data from years 1999-2003. Enterprise size was classified as solo (one worker), micro (2-9 workers), small or medium-sized (SME, $\geq 10$ and $<250$ workers), or unknown size. Previous research shows that self-employed individuals with employees experience more work-related stress than those without employees because of higher job demands (Hessels et al. 2017).

\subsubsection{Hospitalization for stroke and myocardial infarction}

Based on International Classification of Diseases (WHO 2016a), tenth revision (IDC-10), following primary diagnoses for hospitalization were used: acute myocardial infarction (I21), stroke (intracerebral haemorrhage I61, cerebral infarction I63, undetermined pathological type I64). Transient ischaemic attack (G45) and subarachnoid haemorrhage (I60) were excluded in line with previous investigations (Ellekjaer et al. 1999).

\subsection{Statistical analyses}

Stroke and myocardial infarction hospitalization incidence rate ratios (IRR) and 95\% confidence intervals (CI) were estimated using negative binomial regression models. The negative binomial model can be viewed as a generalized version of the Poisson model that is able to appropriately accommodate highly skewed distributions 
of count outcomes, such as those arising from repeat hospital episodes (HES), as well as different individual tendencies for repeat hospitalizations (Rogers et al. 2014; Rogers et al. 2012). All regression models included an offset term representing time at risk for repeat hospitalizations, thereby taking into account that the observed follow-up time differed between individuals, due to death and emigration.

Occupational group and industrial sector were included in all main effects regression models, including the crude models (Model 1). Adjustments for prespecified potential confounding covariates were introduced sequentially. The first series of adjustments included gender, age at inclusion to the cohort, and country of origin (Model 2). The second set of adjustments included previous health status, education level, family structure, number of children, location, and enterprise size (Model 3).

Regression models that included a two-way interaction term between occupational group and industrial sector were estimated to study whether the effect of occupational group was modified by industrial sector. In addition, a model with three-way interaction terms between occupational group, industrial sector, and gender was estimated to further investigate the potential for effect modification by gender. Likelihood ratio tests were used to formally assess the evidence for effect modification. For all statistical tests, the significance level was set to 0.05 .

All statistical analyses were conducted using the Stata software 2013. Stata Statistical Software: Release 13. College Station, TX: StataCorp LP.

\section{Results}

3.1 Population characteristics and hospital episodes due to stroke or myocardial infarction

Of all individuals included in present analyses, 93\% were paid employees, $5 \%$ sole proprietors, and $2 \%$ LLC owners (Table 1). Sole proprietors and LLC owners were older than the employees. The proportion of women was $50 \%$ among employees, and about $30 \%$ among sole proprietors and LCC owners. In all occupational groups, about $70 \%$ of those hospitalized for stroke had only one hospital episode (HES) during the follow-up period. The duration of HES due to stroke varied between 16 to 18 days.
Employees and LLC owners had the longest duration, while sole proprietors had the shortest duration of HES.

The pattern was similar for myocardial infarction as described above for stroke (Table 1). Yet, the HES duration was shorter for myocardial infarction compared with stroke (6 versus 18 days). The majority $(60 \%)$ had only one HES due to myocardial infarction during the follow-up period. The HES duration varied between 5 to 6 days and was longest among sole proprietors and employees and shortest among LLC owners.

Regarding gender differences in hospitalization due to stroke or myocardial infarction, $0.67 \%$ of all men had been hospitalized for stroke compared with $0.34 \%$ of women (Table 2). For myocardial infarction, the corresponding figure was $0.97 \%$ of men and $0.27 \%$ of women. Men had longer HES duration due to stroke than women (18 versus 17.5 days, Table 2), and women had longer HES duration than men due to myocardial infarction (5.9 versus 5.6 days).

Among men, $0.63 \%$ of employees, $1.66 \%$ of sole proprietors, and $0.87 \%$ of LLC owners had been hospitalized due to stroke during the follow-up period. Sole proprietors had shorter HES duration for stroke than LLC owners and employees. Regarding myocardial infarction, $0.92 \%$ of employees, $1.55 \%$ of sole proprietors, and $1.25 \%$ of LCC owners had been hospitalized. Sole proprietors had longer HES duration than employees and LCC owners.

Among women, $0.33 \%$ of employees, $0.59 \%$ of sole proprietors, and $0.47 \%$ of LLC owners had been hospitalized due to stroke. The pattern of HES duration among women differed from that among men. LCC owners had the shortest HES duration due to stroke, followed by sole proprietors and employees. For myocardial infarction, $0.28 \%$ of employees, $0.51 \%$ of sole proprietors, and $0.35 \%$ of LLC owners had been hospitalized. The HES duration was longer among sole proprietors than LLC owners (6.1 days) and employees.

3.2 Hospitalization by occupational group and industrial sector

\subsubsection{Stroke}

Compared with paid employees, the hospitalization incidence rate ratio (IRR) for stroke was 
Table 1 Hospital episodes (HES) due to stroke (ICD10:I61,I63, I64) and myocardial infarction (ICD10: I21) by occupational group

\begin{tabular}{|c|c|c|c|c|}
\hline & Employees & Sole proprietors & $\begin{array}{l}\text { Limited liability } \\
\text { company owners }\end{array}$ & All combined \\
\hline No of individuals & $4,454,845(93 \%)$ & $211,464(5 \%)$ & $109,809(2 \%)$ & $4,776,118(100 \%)$ \\
\hline Mean age at inclusion to the study & $41.8[30.6,53.1]^{*}$ & $49.3[39.5,58.7]^{*}$ & $49.6[41.7,57.7]^{*}$ & $42.3[31.1,53.6]^{*}$ \\
\hline Men & $2,232,506(50 \%)$ & $145,738(69 \%)$ & $80,172(73 \%)$ & $2,458,416(51 \%)$ \\
\hline Women & $2,222,339(50 \%)$ & $65,726(31 \%)$ & $29,637(27 \%)$ & $2,317,702(49 \%)$ \\
\hline \multicolumn{5}{|l|}{ Stroke HES } \\
\hline Individuals with $>0$ HES & 21,361 & 2083 & 834 & 24,278 \\
\hline Total admissions & 30,720 & 2938 & 1233 & 34,891 \\
\hline Duration of HES (mean number of days) & $18.0(29.6) \dagger$ & $16.2(24.9) \dagger$ & $17.9(31.8) \dagger$ & $17.8(29.3) \dagger$ \\
\hline \multicolumn{5}{|l|}{ Distribution of HES due to stroke } \\
\hline 1 & $15,106(70.7 \%)$ & $1501(72.1 \%)$ & $592(70.1 \%)$ & $17,199(70.1 \%)$ \\
\hline 2 & $4317(20.2 \%)$ & $408(19.6 \%)$ & $164(19.7 \%)$ & $4.889(20.1 \%)$ \\
\hline 3 & $1215(5.7 \%)$ & $109(5.2 \%)$ & $38(4.6 \%)$ & $1362(5.6 \%)$ \\
\hline 4 & $474(2.2 \%)$ & $45(2.2 \%)$ & $24(2.9 \%)$ & $543(2.2 \%)$ \\
\hline 5 & $148(0.7 \%)$ & $11(0.5 \%)$ & $5(0.6 \%)$ & $164(0.7 \%)$ \\
\hline$>5$ & $101(0.5 \%)$ & $9(0.4 \%)$ & $11(1.3 \%)$ & $121(0.5 \%)$ \\
\hline \multicolumn{5}{|l|}{ Myocardial Infarction HES } \\
\hline Individuals with $>0 \mathrm{HES}$ & 26,836 & 2588 & 1110 & 30,534 \\
\hline Total admissions & 41,971 & 4081 & 1756 & 47,808 \\
\hline Duration of HES (mean number of days) & $5.7(5.5) \dagger$ & $6.0(6.0) \dagger$ & $5.4(4.6) \dagger$ & $5.7(5.5) \dagger$ \\
\hline \multicolumn{5}{|c|}{ Distribution of HES due to myocardial infarction } \\
\hline 1 & $16,118(60.1 \%)$ & $1547(59.8 \%)$ & $641(57.7 \%)$ & $18,306(60.0 \%)$ \\
\hline 2 & $7331(27.3 \%)$ & $700(27.1 \%)$ & $325(29.3 \%)$ & $8356(27.4 \%)$ \\
\hline 3 & $2743(10.2 \%)$ & $267(10.3 \%)$ & $120(10.8 \%)$ & $3130(10.2 \%)$ \\
\hline 4 & $407(1.5 \%)$ & $48(1.9 \%)$ & $20(1.8 \%)$ & $475(1.5 \%)$ \\
\hline 5 & $161(0.6 \%)$ & $17(0.7 \%)$ & $2(0.2 \%)$ & $180(0.6 \%)$ \\
\hline$>5$ & $76(0.3 \%)$ & $9(0.4 \%)$ & $2(0.2 \%)$ & $87(0.3 \%)$ \\
\hline
\end{tabular}

*25th and 75th percentiles

$\uparrow$ Standard deviation

significantly higher in sole proprietors (IRR 1.71, 95\% CI 1.60-1.83) and LLC owners (IRR 1.67, 95\% CI1.52-1.83) in the unadjusted negative binomial regression model (Table 3, Model 1 for stroke). When adjusting for gender, age, and country of origin (Table 3, Model 2), the estimated associations were no longer observed. No significant differences between the occupational groups were found in the fully adjusted Model 3. However, significant differences were observed by industrial sectors. All industries had higher IRRs compared to the reference category of agriculture, forestry, and fishing. The lowest IRR was in construction (IRR 1.17, 95\% CI 1.04-1.32) and the highest in personal and cultural services (IRR 1.49, 95\% CI 1.33-1.67) compared with the reference category.

\subsubsection{Myocardial infarction}

For MI, the general patterns were similar to those observed in stroke hospitalizations (Table 3, Model 1 for myocardial infarction). Differences observed across occupational groups were statistically significant in the unadjusted Model 1. When adjusted for covariates in Model 2, LLC owners had a significantly lower hospitalization rate (IRR $0.86,95 \%$ CI 0.80-0.93) compared with employees. This association remained when fully adjusted in Model 3 (IRR 
Table 2 Hospital episodes (HES) due to stroke (ICD10:I61,I63, I64) and myocardial infarction (ICD10: I21) by occupational group and gender

\begin{tabular}{|c|c|c|c|c|}
\hline & Employees & Sole proprietors & $\begin{array}{l}\text { Limited liability } \\
\text { company owners }\end{array}$ & All combined \\
\hline \multicolumn{5}{|l|}{ Men } \\
\hline No of individuals & $2,232,506(91 \%)$ & $145,738(6 \%)$ & $80,172(3 \%)$ & $2,458,416(100 \%)$ \\
\hline Mean age at inclusion to the study & $41.8[30.5,53.1]^{*}$ & $49.6[39.7,59.0]^{*}$ & $49.5[41.5,57.6]^{*}$ & $42.6[31.2,53.8]^{*}$ \\
\hline \multicolumn{5}{|l|}{ Stroke HES } \\
\hline Individuals with $>0 \mathrm{HES}$ & 14,028 & 1693 & 695 & 16,416 \\
\hline Total admissions & 20,341 & 2386 & 1043 & 23,770 \\
\hline Duration of HES (mean number of days) & $18.2(29.6) \dagger$ & $16.1(24.5) \dagger$ & $18.6(33.6) \dagger$ & $18.0(29.3) \dagger$ \\
\hline \multicolumn{5}{|l|}{ Myocardial infarction HES } \\
\hline Individuals with $>0$ HES & 20,645 & 2255 & 1006 & 23,906 \\
\hline Total admissions & 32,470 & 3561 & 1590 & 37,621 \\
\hline Duration of HES (mean number of days) & $5.6(5.5) \dagger$ & $5.9(5.5) \dagger$ & $5.3(4.5) \dagger$ & $5.6(5.4) \dagger$ \\
\hline \multicolumn{5}{|l|}{ Women } \\
\hline No of individuals & $2,222,339(96 \%)$ & $65,726(3 \%)$ & $29,637(1 \%)$ & $2,317,702(100 \%)$ \\
\hline Mean age at inclusion to the study & $41.8[30.6,53.0]^{*}$ & $48.7[39.1,57.9]^{*}$ & $50.0[42.1,57.8] *$ & $42.1[31.0,53.3]^{*}$ \\
\hline \multicolumn{5}{|l|}{ Stroke HES } \\
\hline Individuals with $>0$ HES & 7333 & 390 & 139 & 7862 \\
\hline Total admissions & 10,379 & 552 & 190 & 11,121 \\
\hline Duration of HES (mean number of days) & $17.7(29.6) \dagger$ & $16.3(26.7) \dagger$ & $14.5(20.4) \dagger$ & $17.5(29.3) \dagger$ \\
\hline \multicolumn{5}{|l|}{ Myocardial infarction HES } \\
\hline Individuals with $>0 \mathrm{HES}$ & 6191 & 333 & 104 & 6328 \\
\hline Total admissions & 9501 & 520 & 166 & 10,187 \\
\hline Duration of HES (mean number of days) & $5.8(5.5) \dagger$ & $6.8(8.4) \dagger$ & $6.1(5.7) \dagger$ & $5.9(5.6) \dagger$ \\
\hline
\end{tabular}

*25th and 75 th percentiles

$\dagger$ Standard deviation

$0.87,95 \% \mathrm{CI} 0.80-0.94)$ indicating that LLC owners have a $13 \%$ lower risk for hospitalization due to myocardial infarction than paid employees. Furthermore, the IRRs varied by industrial sector. Generally, the estimates were lower for MI than stroke. Lowest hospitalization rate ratios were in trade, transport, and communication (IRR 1.17, 95\% CI 1.07-1.29) and in the not specified industry (IRR $1.17,95 \%$ CI 1.04-1.31), and the highest in personal and cultural services (IRR 1.25, 95\% CI 1.131.38 ) and in the welfare industry (IRR $1.20,95 \%$ CI $1.09-1.32)$ compared to the reference category.

\subsection{Interaction analyses}

In a regression model that included a two-way interaction term between occupational group and industrial sector, no evidence of effect modification was observed for stroke hospitalization $(p$ for interaction $=$ 0.2112 , Table 4$)$. For MI ( $p=0.0111)$, sole proprietors had a higher hospitalization incidence rate ratio in trade, transport, and communication (IRR 1.19, 95\% CI 1.04-1.34) and lower in agriculture, forestry, and fishing (IRR 0.81, 95\% CI 0.68-0.96) compared with paid employees in the same industries. LLC owners had lower hospitalization in trade, transport, and communication (IRR $0.88,95 \%$ CI $0.77-1.00$ ); manufacturing and mining (IRR $0.84,95 \%$ CI 0.70 1.00); financial intermediation and business activities (IRR 0.86, 95\% CI 0.73-1.00); and personal and cultural services (IRR $0.62,95 \%$ CI $0.44-0.88$ ) than paid employees in the same industries. Three-way interaction by occupational group, industrial sector, and gender was not significant. 
Table 3 Stroke and myocardial infarction hospitalization incidence rate ratios (IRR) and 95\% confidence intervals (CI) by occupational group and industrial sector in Sweden between January 1, 2004 and December 31, 2008. Significant associations in bold

\begin{tabular}{|c|c|c|c|c|c|c|c|c|c|c|}
\hline \multicolumn{5}{|l|}{ Stroke } & \multicolumn{6}{|c|}{ Myocardial infarction } \\
\hline Model $1^{1}$ & Mod & $2^{2}$ & Mod & $3^{3}$ & Mod & $11^{1}$ & Mod & $2^{2}$ & Mod & $3^{3}$ \\
\hline IRR $95 \%$ CI & IRR & $95 \% \mathrm{CI}$ & IRR & $95 \% \mathrm{CI}$ & IRR & $95 \% \mathrm{CI}$ & IRR & $95 \% \mathrm{CI}$ & IRR & $95 \% \mathrm{CI}$ \\
\hline
\end{tabular}

\begin{tabular}{|c|c|c|c|c|c|c|c|c|c|c|c|c|}
\hline \multicolumn{13}{|c|}{ Occupational group } \\
\hline Employees & 1.00 & Reference & 1.00 & Reference & 1.00 & Reference & 1.00 & Reference & 1.00 & Reference & 1.00 & Reference \\
\hline Sole proprietors & 1.71 & $1.6-1.83$ & 1.01 & $0.95-1.07$ & 1.03 & $0.95-1.11$ & 1.69 & $1.59-1.8$ & 1.00 & $0.94-1.05$ & 0.99 & $0.92-1.06$ \\
\hline LLC owners & 1.67 & $1.52-1.83$ & 0.97 & $0.89-1.05$ & 1.03 & $0.95-1.12$ & 1.60 & $1.47-1.74$ & 0.86 & $0.80-0.93$ & 0.87 & $0.80-0.94$ \\
\hline \multicolumn{13}{|l|}{ Industrial sector } \\
\hline $\mathrm{AFF}$ & 1.00 & Reference & 1.00 & Reference & 1.00 & Reference & 1.00 & Reference & 1.00 & Reference & 1.00 & Reference \\
\hline TTC & 0.86 & $0.76-0.96$ & 1.34 & $1.21-1.50$ & 1.36 & $1.22-1.52$ & 0.69 & $0.63-0.77$ & 1.08 & $0.98-1.19$ & 1.17 & $1.07-1.29$ \\
\hline MM & 0.99 & $0.88-1.11$ & 1.34 & $1.20-1.49$ & 1.35 & $1.21-1.50$ & 0.90 & $0.82-1.00$ & 1.13 & $1.03-1.24$ & 1.19 & $1.08-1.31$ \\
\hline $\mathrm{C}$ & 0.94 & $0.83-1.07$ & 1.19 & $1.06-1.34$ & 1.17 & $1.04-1.32$ & 0.94 & $0.84-1.05$ & 1.06 & $0.96-1.17$ & 1.08 & $0.98-1.19$ \\
\hline FB & 1.09 & $0.97-1.22$ & 1.24 & $1.11-1.39$ & 1.33 & $1.19-1.49$ & 0.74 & $0.67-0.82$ & 0.90 & $0.82-0.99$ & 1.07 & $0.97-1.18$ \\
\hline PCS & 1.26 & $1.12-1.42$ & 1.44 & $1.28-1.62$ & 1.49 & $1.33-1.67$ & 0.82 & $0.74-0.92$ & 1.11 & $1.01-1.23$ & 1.25 & $1.13-1.38$ \\
\hline NS & 2.72 & $2.38-3.13$ & 1.50 & $1.32-1.71$ & 1.45 & $1.28-1.65$ & 1.73 & $1.53-1.96$ & 1.17 & $1.04-1.31$ & 1.17 & $1.04-1.31$ \\
\hline W & 0.84 & $0.75-0.95$ & 1.23 & $1.10-1.37$ & 1.40 & $1.26-1.56$ & 0.56 & $0.51-0.62$ & 0.94 & $0.86-1.03$ & 1.20 & $1.09-1.32$ \\
\hline
\end{tabular}

$A F F$, agriculture, forestry, and fishing; $C$, construction; $F B$, financial intermediation and business activities; $M M$, manufacturing and mining; $N S$, not specified; PCS, personal and cultural services; TTC, trade, transport, and communication; $W$, welfare industries including education and research, health and social care, public administration, and energy, water and waste management

${ }^{1}$ Unadjusted model

${ }^{2}$ Adjusted for sex, age at inclusion, country of origin

${ }^{3}$ Further adjusted for Charlson Comorbidity Index (none/mild/severe), education level (primary/secondary/tertiary/unknown), family type (alone/lone parent/cohabiting parent/cohabiting/unknown), number of young (0-6 years) and old (7-17 years) children, respectively, enterprise size, and location (urban/rural)

\section{Discussion}

\subsection{Key findings}

Based on Swedish total population register data, this five-year follow-up study investigated differences in hospitalization due to stroke or myocardial infarction between sole proprietors, LLC owners, and paid employees, and whether the associations found varied by industrial sector and gender. LLC owners had $13 \%$ lower hospitalization for myocardial infarction than paid employees. No significant differences between the occupational groups were found for hospitalization for stroke.

However, an increased risk for hospitalization for stroke was found in several industries, for instance trade, transport, and communication; financial intermediation and business activities; and personal and cultural services. Similarly, increased risks were found for hospitalization for myocardial infarction, but these risks were lower than those for stroke, in trade, transport, and communication; personal and cultural services; and welfare industries.

Interaction analyses of occupational group and industrial sector showed that sole proprietors had higher hospitalization for myocardial infarction in trade, transport, and communication and lower hospitalization in agriculture, forestry, and fishing than paid employees in the same industries. LLC owners had lower hospitalization for myocardial infarction in trade, transport, and communication; manufacturing and mining; financial intermediation and business activities; and personal and cultural services compared with paid employees. The results highlight the importance of industrial sector for hospitalization due to acute CVD among sole proprietors and LLC owners. Regarding gender differences, the present study found no significant associations. 
Table 4 Stroke and myocardial infarction hospitalization incidence rate ratios (IRR) and 95\% confidence intervals (CI) by occupational group within level of industrial sector in Sweden 2004-2008

\begin{tabular}{|c|c|c|c|c|c|c|c|c|}
\hline \multirow[t]{3}{*}{ Industrial sector } & \multicolumn{4}{|c|}{ Stroke } & \multicolumn{4}{|c|}{ Myocardial infarction } \\
\hline & \multicolumn{2}{|c|}{ Sole proprietors* } & \multicolumn{2}{|c|}{ LLC owners* } & \multicolumn{2}{|c|}{ Sole proprietors * } & \multicolumn{2}{|c|}{ LLC owners* } \\
\hline & $\mathrm{IRR}^{1}$ & $95 \% \mathrm{CI}$ & $\mathrm{IRR}^{1}$ & $95 \%$ CI & $\mathrm{IRR}^{1}$ & $95 \%$ CI & $\mathrm{IRR}^{1}$ & $95 \% \mathrm{CI}$ \\
\hline Agriculture, forestry, and fishing & 1.10 & $0.9-1.35$ & 0.99 & $0.62-1.60$ & 0.81 & $0.68-0.96$ & 0.87 & $0.60-1.27$ \\
\hline Trade, transport, and communication & 1.08 & $0.94-1.25$ & 1.08 & $0.94-1.24$ & 1.19 & $1.04-1.34$ & 0.88 & $0.77-1.00$ \\
\hline Manufacturing and mining & 1.07 & $0.85-1.35$ & 1.05 & $0.86-1.28$ & 0.94 & $0.77-1.16$ & 0.84 & $0.70-1.00$ \\
\hline Construction & 1.15 & $0.95-1.39$ & 0.90 & $0.72-1.12$ & 1.07 & $0.90-1.26$ & 0.96 & $0.80-1.15$ \\
\hline Financial intermediation and business activities & 1.07 & $0.92-1.25$ & 1.15 & $0.97-1.35$ & 1.08 & $0.93-1.24$ & 0.86 & $0.73-1.00$ \\
\hline Personal and cultural services & 1.04 & $0.86-1.26$ & 0.71 & $0.5-1.04$ & 0.91 & $0.76-1.09$ & 0.62 & $0.44-0.88$ \\
\hline Not specified & 0.82 & $0.69-0.97$ & 0.60 & $0.1-3.60$ & 0.87 & $0.74-1.03$ & 1.10 & $0.23-5.34$ \\
\hline Welfare industries $\dagger$ & 0.99 & $0.74-1.34$ & 1.08 & $0.75-1.55$ & 0.79 & $0.59-1.05$ & 0.99 & $0.71-1.38$ \\
\hline$p$ value for interaction & \multicolumn{4}{|c|}{0.2112} & \multicolumn{4}{|c|}{0.0111} \\
\hline
\end{tabular}

Bold items indicate significant estimates

* The reference group is paid employees

${ }^{1}$ Adjusted for sex, age at inclusion, country of origin, Charlson Comorbidity Index (None/Mild/Severe), education level (primary/ secondary/tertiary/unknown), family type (alone/lone parent/cohabiting parent/cohabiting/unknown), number of young (0-6 years) and old (7-17 years) children, respectively, enterprise size, and location (urban/rural)

†Welfare industries include education and research; health and social care; public administration; energy, water, and waste management

\subsection{Study strengths and limitations}

The study's main strengths are that Swedish register data provided information on the total working population, and included thus employees and all self-employed individuals registered as sole proprietors and LLC owners that were active in the labour market at study baseline in 2003. The study population was followed up for 5 years for hospitalization for stroke or myocardial infarction by record linkage to the hospital discharge register by an encrypted version of the 10-digit personal identity number. Therefore, the outcome measure is not hampered by self-report bias, a common problem in self-reported survey data. Most of the previous research into occupational safety and health (OSH) in relation to CVD has been conducted among employees. Thus, the present research provides new findings on the leading cause of death and disability among sole proprietors and LLC owners. The analyses focused on stroke and myocardial infarction that are acute and severe types of CVD and need immediate hospitalization. Moreover, classification of industrial sectors was based on international standards. Taken together, the results are valid for the total working population in Sweden and are perhaps generalizable to similar working populations. However, total population registers do not include data on work environment factors. We could not analyse the role of work environment for hospitalization which could affect the results. Moreover, this is a follow-up study with measurement of occupational group at baseline (2003). It is plausible that some individuals may change occupational group during the follow-up period (2004-2008) which could influence our findings.

\subsection{Present findings in relation to previous studies}

To our best knowledge, the present study is the first focusing specifically on CVD hospitalization among sole proprietors and LLC owners in comparison to paid employees in same industrial sectors. The findings led to some new insights. First, we used repeat hospitalizations taking into account all hospitalizations during the followup. Even if most hospitalized individuals only had one hospital episode during the follow-up, about $30 \%$ of those experiencing a stroke and $40 \%$ with myocardial infarction had repeat episodes implying that they were hospitalized at several occasions during the follow-up. If we had focused only on the first hospital episode, which is a common strategy in hospitalization studies, we would have lost a fair amount of data. Previous research into mortality among self-employed workers, defined as sole proprietors 
or limited liability company (LLC) owners by the legal form of their enterprise, has indicated higher mortality among sole proprietors than LCC owners (Toivanen et al. 2015). Previous findings state $16 \%$ lower mortality from CVD among LLC owners than employees (Toivanen et al. 2016), which is in line with the present results of $13 \%$ lower hospitalization for myocardial infarction in LLC owners than in paid employees.

Second, we identified industries with the highest risk for hospitalization due to stroke or myocardial infarction. As in previous studies (Toivanen et al. 2016; Toivanen et al. 2015), trade, transport, and communication was singled out as a troublesome industry with increased risk for hospitalization for both stroke and myocardial infarction. However, interaction analyses found that this was the case only among sole proprietors in relation to myocardial infarction. LLC owners on the other hand had actually lower hospitalization for myocardial infarction in trade, transport, and communication than employees in the same industry. Moreover, they had had lower risk for hospitalization than employees in manufacturing and mining; financial intermediation and business activities; and personal and cultural services. Thus, this finding confirms that LLC owners are generally a healthier group compared to employees in terms of hospitalization due to myocardial infarction.

\subsection{Possible mechanisms behind the associations}

The excess risk of hospitalization for stroke or myocardial infarction that was identified for most industrial sectors compared to the reference category may partly depend on industry-specific factors such as varying market competition, working conditions, and work environment factors. For instance, it may be that some industries such as trade, transport, and communication and personal and cultural services that also include hotels and restaurants have more psychosocial stress which has been associated with increased risk for CVD (Belkic et al. 2004; DeVries et al. 2003). The present results indicate that sole proprietors in trade, transport, and communication had an increased for hospitalization for myocardial infarction, but LLC owners had a lower risk compared with paid employees in the same industry. In line with the literature on social hierarchies (Sapolsky 2005), it may be that the working conditions of sole proprietors are more stressful than of the other occupational groups due to more financial insecurity, less control over work, and perhaps less work-family balance. Regarding enterprise legal form, it is plausible that sole proprietors experience more work stress due to financial demands than LLC owners, as they are personally responsible for all transactions. Financial stress is suggested to be a major category of entrepreneurial stressors (Grant and Ferris 2012; Lechat and Torrès 2017).

Working life is changing due to global competition, ageing working populations, and the need to integrate refugees and other groups in a vulnerable situation into the labour market, all of which can lead to an increase in new forms of employment including self-employment. Therefore, it is important to monitor working conditions among the sole proprietors particularly in trade, transport, and communication because the conditions may be more detrimental than in other industries for the health and well-being of this occupational group.

\subsection{Conclusions}

More research is needed that considers both industry and work environment factors in relation to CVD in the self-employed, bearing in mind that previous occupational safety and health research has mainly been conducted among paid employees. Even if the present study did not establish any gender differences, future studies should consider gender due to segregated labour markets and perhaps different motivation for becoming selfemployed among women and men. The differences in hospitalization by industrial sector found in the present study provide information to further investigation of working conditions and health in those industries with higher risks for hospitalization. The results contribute to policy strategies aimed at improving well-being among working populations in general and self-employed individuals in particular.

Acknowledgements The authors would like to thank the organizers and participants at the 1 st international research seminar on the health of entrepreneurs and small business owners at Montpellier Business School, September 2016, and a seminar at the Centre for Health Equity Studies, Stockholm University/Karolinska Institutet for helpful comments on an earlier version.

Funding information This study is financially supported by the Swedish research council for health, working life and welfare (FORTE), project number 2012-0615. 
Open Access This article is distributed under the terms of the Creative Commons Attribution 4.0 International License (http:// creativecommons.org/licenses/by/4.0/), which permits unrestricted use, distribution, and reproduction in any medium, provided you give appropriate credit to the original author(s) and the source, provide a link to the Creative Commons license, and indicate if changes were made.

\section{References}

Andersson, P. (2007). [How is to be self-employed in Sweden?] Hur är det att vara egenföretagare i Sverige? Ekonomisk debatt, 35(6), 7-18.

Andersson, P. (2008). Happiness and health: well-being among the self-employed. Journal of Socio-Economics, 37(1), 213-236.

Aronsson, G., \& Gustafsson, K. (2005). Sickness presenteeism: prevalence, attendance-pressure factors, and an outline of a model for research. Journal of Occupational and Environmental Medicine, 47(9), 958-966.

Belkic, K. L., Landsbergis, P. A., Schnall, P. L., \& Baker, D. (2004). Is job strain a major source of cardiovascular disease risk? [Review ]. Scandinavian Journal of Work, Environment \& Health, 30(2), 85-128.

Brunner, E. J. (2017). Social factors and cardiovascular morbidity. Neuroscience \& Biobehavioral Reviews, 74(Part B), 260-268.

Charlson, M. E., Pompei, P., Ales, K. L., \& MacKenzie, C. R. (1987). A new method of classifying prognostic comorbidity in longitudinal studies: development and validation. Journal of Chronic Diseases, 40(5), 373-383.

DeVries, A. C., Glasper, E. R., \& Detillion, C. E. (2003). Social modulation of stress responses. Physiology \& Behavior, 79(3), 399-407.

Dolinsky, A. L., \& Caputo, R. K. (2003). Health and female selfemployment. Journal of Small Business Management, 41(3), 233-241.

Ellekjaer, H., Holmen, J., Kruger, O., \& Terent, A. (1999). Identification of incident stroke in Norway: hospital discharge data compared with a population-based stroke register. Stroke, 30(1), 56-60.

European Commission, \& Eurostat (2013). Statistical classification of economic activities in the European community, Rev. 1. $1 \quad\left(\begin{array}{llll}2 & 0 & 0 & 2\end{array}\right)$. h t t p : / / e c . e u r o p a . eu/eurostat/ramon/nomenclatures/index.cfm?TargetUrl= L S T $\_\mathrm{NOM}_{-}$D T L \& S t r N o m $=\mathrm{NACE}_{-} 1_{-} 1$ $\&$ StrLanguageCode $=$ EN\&IntPcKey $=\&$ StrLayoutCode $=\overline{\mathrm{EN}}$. Accessed 22 Jul 2015.

Grant, S., \& Ferris, K. (2012). Identifying sources of occupational stress in entrepreneurs for measurement. International Journal of Entrepreneurial Venturing, 4(4), 351-373.

Grosheide, E., \& Barenberg, M. (2015). Minimum fees for the self-employed: a European response to the "Uber-ized" economy. Columbia Journal of European Law, 22, 193-236.

Gunnarsson, K., Vingard, E., \& Josephson, M. (2007). Self rated health and working conditions of small-scale enterprisers in Sweden. Industrial Health, 45(6), 775-780.

Hatfield, I. (2015). Self-employment in Europe. London: Institute for Public Policy Research.
Hessels, J., Rietveld, C. A., \& van der Zwan, P. (2017). Selfemployment and work-related stress: the mediating role of job control and job demand. Journal of Business Venturing, 32(2), 178-196.

Hobbs, F., Piepoli, M., Hoes, A., Agewall, S., Albus, C., Brotons, C., et al. (2016). 2016 European Guidelines on cardiovascular disease prevention in clinical practice. European Heart Journal, 37(29), 2315-2381.

International Commission on Occupational Health (2017). www. icohweb.org/.

Jamal, M. (1997). Job stress, satisfaction, and mental health: an empirical examination of self-employed and non-selfemployed Canadians. Journal of Small Business Management, 35(4), 48-57.

Joona, P. A., \& Wadensjö, E. (2008). A note on immigrant representation in temporary agency work and self-employment in Sweden. Labour, 22(3), 495-507.

Kivimäki, M., \& Kawachi, I. (2015). Work stress as a risk factor for cardiovascular disease. Current Cardiology Reports, 17(9), 1-9.

Knani, M., Fournier, P.-S., \& Biron, C. (2015). Sickness presenteeism in SMEs: a critical review. The Business \& Management Review, 6(4), 271.

Kuper, H., Adami, H. O., Theorell, T., \& Weiderpass, E. (2007). The socioeconomic gradient in the incidence of stroke. A prospective study in middle-aged women in Sweden. Stroke, 38(1), 27-33.

Lechat, T., \& Torrès, O. (2017). Stressors and satisfactors in entrepreneurial activity: an event-based, mixed methods study predicting small business owners' health. International Journal of Entrepreneurship and Small Business, 32(4), 537-569.

Mckay, J., Mensah, G. A., Greenlund, K., Mendis, S., \& World Health Organization. (2005). The atlas of heart disease and stroke. Geneva: World Health Organization.

Nordenmark, M., Vinberg, S., \& Strandh, M. (2012). Job control and demands, work-life balance and wellbeing among selfemployed men and women in Europe. Vulnerable Groups \& Inclusion, https://doi.org/10.3402/vgi.v3i0.18896.

Pedersini, R., \& Coletto, D. (2010). Self-employed workers: industrial relations and working conditions. Dublin: European Foundation for the Improvement of Living and Working Conditions.

Rietveld, C. A., van Kippersluis, H., \& Thurik, A. R. (2015). Selfemployment and health: barriers or benefits? Health Economics, 24(10), 1302-1313.

Rogers, J. K., McMurray, J. J. V., Pocock, S. J., Zannad, F., Krum, H., Van Veldhuisen, D. J., et al. (2012). Eplerenone in patients with systolic heart failure and mild symptoms: analysis of repeat hospitalizations. Circulation, 126(19), 2317-2323.

Rogers, J. K., Pocock, S. J., McMurray, J. J. V., Granger, C. B., Michelson, E. L., Ostergren, J., et al. (2014). Analysing recurrent hospitalizations in heart failure: a review of statistical methodology, with application to CHARM-preserved. European Journal of Heart Failure, 16(1), 33-40.

Sapolsky, R. M. (2005). The influence of social hierarchy on primate health. Science, 308(5722), 648-652.

Sevä, I. J., Vinberg, S., Nordenmark, M., \& Strandh, M. (2016). Subjective well-being among the self-employed in Europe: macroeconomy, gender and immigrant status. Small Business Economics, 46(2), 239-253. 
Statistics Sweden (2004). SNI Swedish Standard Industrial Classification 2002. http://www.foretagsregistret.scb. se/sni/040115snisorteradeng.pdf. Accessed Feb 192014.

Statistics Sweden. (2007). Some essential terms for the area of labour market in official statistics. Örebro: Statistics Sweden.

Stephan, U. (2018). Entrepreneurs' mental health and well-being: A Review and Research Agenda. The Academy of Management Perspectives, Published online before print, https://doi.org/10.5465/amp.2017.0001.

Stephan, U., \& Roesler, U. (2010). Health of entrepreneurs versus employees in a national representative sample. Journal of Occupational and Organizational Psychology, 83(3), 717-738.

Toivanen, S. (2008). Job control and the risk of incident stroke in the working population in Sweden. Scandinavian Journal of Work, Environment \& Health, 34(1), 40-47.

Toivanen, S., Mellner, C., \& Vinberg, S. (2015). Self-employed persons in Sweden - mortality differentials by industrial sector and enterprise legal form: a five-year follow-up study. American Journal of Industrial Medicine, 58(1), 21.

Toivanen, S., Härter Griep, R., Mellner, C., Vinberg, S., \& Eloranta, S. (2016). Mortality differences between self- employed and paid employees: a 5-year follow-up study of the working population in Sweden. Occupational and Environmental Medicine, 73(9), 627-636.

Vinberg, S., Gundersen, K. T., Nordenmark, M., Larsson, J., \& Landstad, B. J. (2013). Entrepreneurs' health-the importance of psychosocial working conditions and individual factors. International Journal of Entrepreneurial Venturing, 4(4), 374-390.

WHO (2016a). International statistical classification of diseases and related health problems 10th Revision, Version for 2004. http://apps.who.int/classifications/apps/icd/icd10online2004 /fr-icd.htm2015.

WHO (2016b). New initiative launched to tackle cardiovascular disease, the world's number one killer. http://www.who. int/cardiovascular_diseases/en/2017.

WHO (2017). The top 10 causes of death. http://www.who. $\mathrm{int} /$ mediacentre/factsheets/fs310/en/2017.

Yoon, J., \& Bernell, S. L. (2013). The effect of self-employment on health, access to care, and health behavior. Health, 5(12), 2116. 